\title{
A ESCOLA REFLEXIVA E APRENDIZAGEM FORMADORA DE CIDADANIA.
}

\author{
MARDILED TANIA VILHENA VIEIRA GOMES
}

\section{RESUMO}

Este artigo buscou analisar "A escola reflexiva e a aprendizagem formadora de cidadania dos alunos do 5 ano da Escola Municipal de Ensino Fundamental I Gumercindo Gomes Pereira no município de Tucuruí-PA, no ano de 2017.A metodologia utilizada foi o estudo Misto com desenho DITRAS, tendo o enfoque quantitativo direcionado pelo alcance exploratório seguido do bibliográfico e Analítico. O estudo teve os seguintes objetivos: Descrever o papel da escola reflexiva e sua contribuição para a formação da cidadania discente no contexto educacional. Evidenciar a importância da formação docente para desenvolvimento da prática pedagógica na formação discente no âmbito de ensino. Relatar de que maneira as dificuldades de aprendizagem dos alunos do $5^{\circ}$ ano vêm sendo superada pela prática pedagógica docente, no desenvolvimento do processo ensino aprendizagem. Ainda existe muitos desafios e dificuldades a serem superados, mas a escola já apresenta novas perspectivas em termo dos resultados alcançados, promovendo mudanças necessárias para aquisição de uma educação democrática, de qualidade compromissada com a cidadania.

Palavras-chave: Escola. Reflexiva. Aprendizagem. Formadora. Cidadania.

\begin{abstract}
This work aimed to analyze "The reflective school and the learning to form citizenship of the 5th year students of the Municipal Elementary School I Gumercindo Gomes Pereira in the municipality of Tucuruí-PA, in 2017. The methodology used was the Mixed study with DITRAS design, with the quantitative focus directed by exploratory reach followed by the bibliographic and analytical. The study had the following objectives Describe the role of the reflective school and its contribution to the formation of student citizenship in the educational context. To highlight the importance of teacher training for the development of pedagogical practice in student education in the teaching field. To report how the learning difficulties of 5th graders have been overcome by the pedagogical teaching practice, in the development of the teaching learning process. There are still many challenges and difficulties to be overcome, but the school already presents new perspectives at the end of the results achieved, promoting changes necessary for the acquisition of a democratic education, of quality committed to citizenship.
\end{abstract}

Keywords: School. Reflective. Apprenticeship. Trainer. Citizenship. 


\section{INTRODUÇÃO}

Existe uma recorrência nas instituições escolares quanto o fator qualidade educacional, diversos fatores esterno que influenciam o desempenho da aprendizagem, e que podem agravar as dificuldades dos alunos na assimilação de certos conteúdos. A escola conservadora mostra-se ultrapassada no sentido o tratamento da educação. A dificuldade dos alunos existe e precisa de uma solução, mas o que se observa é que todo trabalho de solução parece não obter o resultado esperado. Aparentemente, o método, exaustivamente, aplicado funciona provisoriamente. Todavia, não pela eficiência, mais sim, pela falta de explanação de outras possibilidades melhores e mais efetivas. Abordar esse assunto é importante, pois possibilita o repensar da ação docente, principalmente em termo do fator qualidade de ensino.

Algo precisa mudar para que o resultado seja diferente, e essa mudança deve partir da escola como instituição responsável por aquilo que se propõem que é o ato de educar crianças e formá-los para a sociedade em princípios de sua cidadania.

Necessita-se mudar a maneira como se encara isso. Da maneira como as coisas são tratadas comprovou-se ineficiência da educação diante dos dados estatísticos apontado pelo último censo escolar, pois o objetivo proposto, para a aquisição da qualidade de ensino nas escolas públicas brasileiras não é alcançado como meta estabelecida. Logo, a necessidade de mudar a proposta para mudar a resposta.

Para que essa mudança ocorre se faz necessário pensar e repensar a finalidade da educação pública brasileira, nesse contexto direciona-se a temática dessa investigação que visa analisar "A escola reflexiva e a aprendizagem formadora de cidadania dos alunos do $5^{\circ}$ ano da Escola Municipal de Ensino Fundamental I Gumercindo Gomes Pereira no município de Tucuruí-PA, no ano de 2017.

A educação pública brasileira em termo da formação do aluno, principalmente no que se refere sua criticidade e cidadania, representa um desafio enorme em busca de novas trilhas para a aplicabilidade da prática docente, que estimule o aluno a pensar criticamente sobre o mundo. Promovendo a ele uma educação de qualidade.

Professores, e profissionais da educação buscam mecanismo para promover uma aprendizagem significativa e contextualizada que o aluno seja capaz de ser agente construtor de seu conhecimento, onde ele seja estimulado a percorrer, trilhar, descobrir novos caminhos, sendo sujeito pesquisador, inovador, criador, e transformador de sua aprendizagem. Neste sentido cabe as escolas públicas brasileiras como instituição compromissada com a educação ressignificar sua missão enquanto instituição que realiza numa intencionalidade sistematizada do ensino, atrelada aos princípios filosóficos, epistemológicos, sociais, educacionais. Visando promover através da educação uma 
reflexão contínua sobre a realidade formando cidadão críticos e reflexivos capazes de transformar a si e a seu próprio contexto.

A escola precisa resgatar sua identidade buscar ressignificar seu fazer pedagógico visando promover um conhecimento que esteja atrelado com a função social da escola. Vale ressaltar para que haja essa mudança se faz necessário que todos os seguimentos escolares assumam seu papel promovendo um pensar e repensar através de uma reflexão contínua sobre as problemáticas e as finalidades que se almeja com a educação.

Os alunos estão adentrando o segundo nível do ensino fundamental menor ( $5^{\circ}$ ano) sem domínio da leitura e da escrita, e o que mais preocupa e a ausência de formação da criticidade desses alunos. A maioria dos alunos neste nível de ensino não conseguem fazer uma interpretação do que leem.

A escola ainda em pleno século XXI assume uma triste característica de repassadora de informações onde os alunos são meros receptores destas. Grande parte dos discentes nesse nível de ensino mostram-se incapazes de agir com autonomia e independência frente a construção de seus conhecimentos, preferem receber tudo pronto. Não são estimulados a pesquisar, criar, problematizar, argumentar, debater, discutir, analisar, parecem estarem estagnados a pensar criticamente sua realidade.

A modernização do século XXI frente aos aparatos tecnológicos que trouxe a facilitação e acesso ao conhecimento, trouxe também muitos problemas junto em termo do desenvolvimento do aluno.

Hoje os alunos vão ao computador fazem Ctrl + C e Ctrl + C simultaneamente (cópia e cola) de trabalhos divulgados na rede, sem se quer saber a veracidade e qualidade deles. Não fazem uso da leitura e muito menos pesquisa de maneira correta como deveria ser. E o que mais preocupa em tudo isso é ver professores omissos a essa realidade atribuindo notas a aluno sem se quer saber a origem desses trabalhos. As deficiências são de diversas ordens, e chegamos a essa triste realidade de turmas de ( $5^{\circ}$ ano) lotadas com maioria dos alunos sem domínio da leitura e da escrita e sem criticidade alguma em termo de sua formação.

Vivenciando essa triste realidade por muitos anos como professora de escola pública que surge a problemática deste estudo com a interrogante "Qual o papel da escola reflexiva e sua contribuição para a aprendizagem formadora de cidadania alunos do $5^{\circ}$ ano da Escola Municipal de Ensino Fundamental I Gumercindo Gomes Pereira no município de Tucuruí-PA, no ano de 2017 ?

Para melhor compreensão da problemática apresenta-se o lócus de investigação onde as deficiências e os conflitos em termo da problemática estão presentes no espaço escolar. Neste contexto apresenta-se o município de Tucuruí localizado no estado do Pará. 
Este município localiza-se a mesorregião do Sudeste do Pará, Microrregião de Tucuruí, situado a margem esquerda, e é banhado pelo Rio Tocantins. O município possui uma área 2.086,20 km², sendo 33,22 km² de área urbana e 2.095,48 km² de área rural. Ele faz limite ao sul novo repartimento, ao Norte com Baião, a Leste Breu Branco e a Oeste Pacajá.

Referente a metodologia utilizada nesta investigação se fez uso do estudo Misto com desenho DITRAS, tendo o enfoque quantitativo direcionado pelo alcance exploratório seguido do bibliográfico e Analítico. Para definição do tipo de pesquisa os autores (SAMPIERI; CALLADO; LUCIO, 2013, p. 21), apresentam a pesquisa sistemática, empírica e crítica. Isso se aplica tanto a estudos quantitativos, qualitativos ou mistos. Apresenta a pesquisa Mista para esta investigação, pois o método misto envolve a ação da pesquisa quantitativa e qualitativa em um mesmo processo investigativo se completando e articulando entre si, pois segundo (SAMPIERI; CALLADO; LUCIO, 2013, p. 21), "amplia o conhecimento dos dados subjetivos e objetivos, utilizando dados estatísticos para complementar a análise qualitativa". SAMPIERI, COLLADO E LUCIO, 2013.p.569), afirmam que o desenho se refere ao plano de ação ou a estratégia criada para obter a informação que se deseja. Assim, a pesquisa fez uso do desenho transformador sequencial (DITRAS) uma vez que se utilizara de duas etapas para coletar os dados, em que não há uma ordem especifica para iniciar a coleta pode ser tanto a qualitativa como a quantitativa, em que os resultados de ambas são integrados durante as analises interpretativas, esse desenho de investigação tem o objetivo principal de colaborar com a perspectiva teórica do pesquisador e em ambas as fases ele deve considerar as vozes e as opiniões de todos os participantes ou grupos que serão analisados. Cabem a pesquisadora escolher por qual fase iniciar sua pesquisa.

Tem termo da definição do alcance a pesquisa passa ter o alcance inicialmente exploratório, seguido do bibliográfico e finalizando com o analítico. Para PADILHA (2014) toda pesquisa parte de um alcance inicialmente exploratório, onde a pesquisadora busca explorar desde o campo de investigação, as bibliografias, as técnicas e métodos para dar um bom suporte a pesquisa. Para SAMPIERI, COLLADO E LUCIO (2013) essa escolha se encaixa perfeitamente na característica do estudo de natureza mista, pois usa-se respectivamente métodos e técnicas qualitativas e quantitativas para a coleta e análise dos dados.

A pesquisa exploratória segundo GIL (1995, p. 44), tem como "foco desenvolver, explicar e modificar conceitos e ideias, com vistas na resolução de problemas mais sucintos ou hipóteses analisáveis para estudos posteriores". O que será considerável e visível na proposta apresentada para analisar as variáveis em evidência neste trabalho.

O estudo teve os seguintes objetivos: Descrever o papel da escola reflexiva e sua contribuição para a formação da cidadania discente no contexto educacional. Evidenciar a importância da formação docente para desenvolvimento da prática pedagógica na formação 
discente no âmbito de ensino. Relatar de que maneira as dificuldades de aprendizagem dos alunos do $5^{\circ}$ ano vêm sendo superada pela prática pedagógica docente, no desenvolvimento do processo ensino aprendizagem.

Os alunos estão adentrando o ensino fundamental maior com muitas deficiências principalmente em termo das habilidades da leitura e da escrita. Alunos que não conseguem fazer uma interpretação simples de um texto pequeno. Essa ausência da leitura interfere diretamente na produtividade da escrita, alunos com deficiência de leitura não conseguem produzir redações, não conseguem fazer uma interpretação crítica e reflexiva de um problema apresentado a ele.

Os alunos do contexto atual estão cada vez mais afastados de sua formação global, estão acostumados a receber tudo pronto e acabado, sentem preguiças e dificuldade de pensar para achar determinada solução em que a pesquisa está cada vez mais ausente de suas ações educativas.

Diante de tais problemáticas se faz necessário descrever a escola onde realizou-se a investigação, a contextualização busca descrever a E.M.E.F. Gumercindo Gomes Pereira, buscando realizar uma reflexão que perpassa pela conjuntura física, pedagógica, administrativa e familiar. Visando o entendimento da prática docente aplicada no dia a dia da escola compromissada com a formação do aluno em todos os seus aspectos. Evidenciando ainda a importância da formação dos profissionais da educação para a formação de uma escola reflexiva.

\section{A ESCOLA REFLEXIVA SUA IMPORTÂNCIA PARA A EDUCAÇÃO.}

As mudanças de que temos vindo falar não se situam só ao nível dos alunos e dos professores. Elas estendem-se ao nível da organização que é a escola.

Essa alteração dos processos de aprendizagem implica também uma nova organização da escola, com tempos e lugares diferenciados, não só para estar em aulas de grandes grupos, mas também para trabalhar em pequenos grupos ou isoladamente, com acesso facilitado tanto a livros e revistas quanto a computadores e bases de dados e aos serviços da internet, com tempos e espaços para a realização de tarefas concretas, interpelativas da teoria e concretizadoras destas, pois é na interação entre o saber dos outros e a sua aplicação por cada um a uma situação concreta que cada um desenvolver o seu saber (Tavares e Alarcão, 2001: 107-108).

As escolas que já perceberam o fenômeno começaram a funcionar como comunidades, aprendentes, reflexivas. Constituem aquilo a que chamei a escola reflexiva que defini como Organização que continuadamente se pensa a si própria, na sua missão 
social e na sua organização, e se confronta com o desenrolar da sua atividade em um processo heurístico simultaneamente avaliativo e formativo (Alarcão, p. 25. 20011).

A escola reflexiva não é telecomandada do exterior. É autogerida. Tem o seu projeto próprio, construído com a colaboração dos seus membros. Sabe para onde quer ir e avaliase permanentemente na sua caminhada. Contextualiza-se na comunidade que serve e com esta interage. Acredita nos seus professores, cuja capacidade de pensamento e de ação sempre fomenta. Envolve os alunos na construção de uma escola cada vez melhor. Não esquece o contributo dos pais e de toda a comunidade. Considera-se uma instituição em desenvolvimento e em aprendizagem. Pensa-se e avalia-se. Constrói conhecimento sobre si própria.

Uma escola reflexiva é uma comunidade de aprendizagem e é um local onde se produz conhecimento sobre educação. Nesta reflexão e no poder que dela retira toma consciência de que tem o dever de alertar a sociedade e as autoridades para que algumas mudanças a operar são absolutamente vitais para a formação do cidadão do século XXI. Vem a propósito aqui mencionar a introdução das novas tecnologias. Alguns países compreenderam a importância da escola na educação dos jovens cidadãos e aposentam numa educação dos jovens cidadãos e apostam numa educação autonomizante e atual. Numa escola deste tipo a gestão da informação é muito importante.

É preciso organizar o pensamento para compreender e poder agir. É esta ideia que é preciso introduzir nos paradigmas de formação das pessoas e de funcionamento das instituições. Será está a minha mensagem. O resto são ferramenta. Úteis, sem dúvida. Mas apenas ferramentas.

Antunes (2003) fala que um professor mal preparado e ingênuo, ao acreditar que ensina, não requer muitas horas de cuidados críticos e estratégicos para que se transforme e assim transforme a aprendizagem dos alunos. Como os diplomas dos professores possuem a absurda "validade perene", seria imprescindível um trabalho sistemático de ajuda e preparo de aulas, orientação e leitura. Habituamo-nos às vaias dos professores quando se sugere, com bom humor, que todo diploma para exercício no magistério deveria, assim como o certificado de habilitação para dirigir veículos, possuir prazo de validade limitado e plena meritocracia para essa revitalização.

Ao aproximar os pais da escola indaga-se com muita lógica o que poderá indagar-se com muita lógica o que poderá dar sentido e consistência a essa aproximação. Os itens seguintes sugerem interessantes iniciativas:

Acompanhamento do desenvolvimento intelectual e social dos filhos. É sempre muito importante para uma criança ou um adolescente que seus pais mostrem interesse por suas atividades, acompanhando seu progresso e envolvendo-os em diálogos sobre seus amigos, suas atividades e seus sonhos. É muito evidente a evolução de um aluno cercado de adulto 
que assistem seu crescimento, promovem sua autoestima e revelam acentuado interesse por seu desempenho cognitivo e relacional.

Apoiando os professores no estabelecimento de limites e na firmeza e coerência com que filhos e alunos assumam e compreendam o "não". O verdadeiro sentido da afetividade consiste em inspirar segurança e desenvolver capacidades para a superação de desafios. Nesse sentido, o papel da escola e da família é cobrar coerência - e rigor, se necessário no cumprimento de normas, princípios e regras. Não se trata de o professor procurar o pai para pedir que aplique sanções ao filho nem vice-versa, mas a partir de uma linguagem comum, normas procedimentais e valores, discutidos, devem ser assumidos por todos. Empenho e dedicação em assumir quadro de valores e referências que expressem a mesma linguagem utilizada na escola.

O papel, tanto da escola quanto da família, consiste em desenvolver nos alunos e nos filhos um quadro referencial de valores. Entretanto, essa ação só se concretiza se pais e professores conversarem e assumirem consensualmente ideias comuns sobre honestidade, coragem, otimismo, integridade, autoestima, persistência, iniciativa, companheirismo e outros valores.

O domínio do professor deve se concentrar no campo crítico e pedagógico, pois assim ele evita ser vítima de imposição tecnológica na sala de aula, e pode ter a opção de integrar ou não a tecnologia em seu currículo, de acordo com os objetivos e competências a serem desenvolvidos, e ainda escolher o momento apropriado para fazê-lo. O professor não pode perder a dimensão pedagógica (LEITE, 2010, p. 16).

$\mathrm{Na}$ escola, mesmo socializadora como todos os processos sociais, deveria preponderar a construção da consciência crítica e autocrítica, dentro da perspectiva da formação do sujeito. Educação reclama postura de sujeito. É o cerne da emancipação, que somente medra em sujeitos. Emancipação emerge, quando objetos se apercebem de sua subordinação, e, um processo de conquista, avançam para a condição de sujeitos.

Não é incomum ouvirmos a frase: "Ah, os alunos de hoje não são mais os mesmos". Quando alguém diz isso, está demonstrando sanidade mental. É claro que os alunos de hoje não são mais os mesmos. Mas essa expressão pode indicar uma certa distorção pedagógica. Afinal, alguém diz isso e, ainda assim, continua dando aula do mesmo jeito que dava há dez ou quinze anos? Se ao aluno não são mais os mesmos, se o mundo não é mais o esmo, como fazer do mesmo modo? Há alguns aspectos na área da Educação que precisam ter uma durabilidade maior, mas há algo que não podemos esquecer: a importância de olhar a realidade, afinal de contas, a Educação lida com o futuro: 
Essa aprendizagem deve se expressar pela ressignificação do processo educacional e das práticas de ensinar. Trata-se de conceber uma elaboração curricular que permitam ao professor estabelecer pontes entre sua história, suas aprendizagens ao longo da vida e as maneiras próprias de estar e ser no mundo, com as teorias as práticas, as suas e as dos outros (DEUS; MENDES, 2011, p.148).

De um lado, o fato de a Educação Escolar, na intenção de fazer um futuro coletivo melhor, constituir-se em espaço de práticas múltiplas, com múltiplas determinações e sob múltiplas formas de controle, pode nos colocar em um estado de cautela tal que nos provoque a imobilização. Por outro, a urgência das mudanças, a precariedade atual do trabalho educativo e a inconformidade resultante dessa situação podem nos induzir a um ímpeto tal que inviabilize a realização das possibilidades.

Por isso, o alcance da necessidade harmonia entre uma salutar cautela e um eficiente ímpeto não se origina nem do uso exclusivo de uma interpretação pessoal de cada educador - interpretação sujeita a desvios e equívocos, por situar-se entre outras práticas -, nem da desconsideração apressada dos condicionamentos concretos que preenchem a Educação Escolar.

A Paciência histórica é saber ver o momento em que as coisas acontecem e observar se estão suficientemente maduras para poderem ser mexidas. Há uma frase muito comum (quem é do interior sabe disso) que diz: "é muito perigoso ter razão antes da hora". Paciência histórica é a capacidade de perceber que as coisas têm um momento. Aliás, FREIRE (2014) diz algo fundamental: "Se você não fizer hoje o que hoje pode ser feito, e tentar fazer hoje o que hoje não pode ser feito, dificilmente fará amanhã o que hoje deixou de fazer, porque as condições se alteram". Paciência histórica é a percepção do momento adequado em que as coisas podem ser alteradas.

A Paciência pedagógica significa a capacidade de observar que as pessoas têm processos distintos de aprendizagem e de ensino, que os alunos, os colegas de profissão vivem momentos diferentes. É necessário que haja uma maturação na possibilidade de permuta de informação e conhecimento. E paciência afetiva é a capacidade de amorosidade que precisa o tempo todo cobrir qualquer ato pedagógico, de maneira que não se incorra na agressividade ou na ruptura do padrão de autonomia e liberdade que alguém carrega. Paciência afetiva é olhar a outra pessoa como outra pessoa e não como alguém estranho.

Para que essas cenas não se tornem cada vez mais banalizadas, é preciso ter a capacidade de fazer um projeto pedagógico sólido na Escola com as famílias. Essa é uma tarefa conjunta.

Cada Escola tem de se organizar como uma força-tarefa para impedir que haja uma degeneração na convivência. A clássica frase "quem sai aos seus não degenera" pode ser substituída pode ser substituída por "quem sai aos seus não regenera". É preciso uma 
regeneração dessa questão numa convivência, num espaço que não seja arcaico, em que a tecnologia tenha a sua presença, que o ensino não seja de conteúdos abstratos, mas que sejam ideias que tragam a reflexão do concreto, em que não haja autoritarismo, mas que a autoridade seja um elemento de constituição sólida da convivência, em que haja uma estrutura colaborativa em vez de trabalhar apenas como competição.

O trabalho de Educação é coletivo, é feito com as pessoas. É esse ato coletivo que nos coloca o imperativo de nos desenvolvermos coletivamente também. E, para isso, é preciso acreditar em dois grandes princípios: Quem sabe reparte e quem não sabe procura! Porque se aquele que sabe, não repartir, enfraquece aos outros e a si mesmo.

O ensino exige um professor capaz de desenvolver habilidades intelectuais junto aos alunos, capaz de desenvolver bem o conteúdo, e de bem conhecer os caminhos e os procedimentos de como fazer o aluno chegar a sua aprendizagem (Saraiva; Lima 2011, p. 271)

Os processos educativos escolares não devem se adaptar às inovações, mas integrar novas formas ao seu cotidiano. Adaptar é postura passiva, enquanto integrar pressupõe metas de convergência. As tecnologias mais recentes podem fazer parte do trabalho pedagógico escolar, desde que utilizadas como ferramentas a serviço de objetivos educacionais que estejam claros para a comunidade. Repito: tecnologia em si não é sinal de mentalidade moderna; o que moderniza é a atitude e a concepção pedagógica e social que se usa e, assim, uma mentalidade moderna lança mão da tecnologia por incorporar-se aos seus projetos, e não simplesmente por ser tecnologia.

Evidentemente, uma Escola precisa atuar no seu dia a dia com um poio pedagógico que traga a possibilidade de entendermos que, de fato, estamos no século XXI. Não apenas porque mudou uma datação, mas por algo que é especial: a nossa capacidade de não ficarmos ultrapassados. Isso poderá ocorrer não por nos tornarmos antigos, mas se nos ficarmos velhos, isto é, se a nossa cabeça envelhecer.

[...] práticas e situações cotidianamente vivências pelos professores e demais profissionais das equipes técnicas das escolas podem gerar pensamentos, problematizações, interrogações, questionamentos que, por sua vez, são capazes de desencadear ações, mecanismos, movimentos, individuais e coletivos, de busca de soluções e respostas, cujo desenvolvimento, por seu turno, pode promover mudanças e gerar novas situações (GIOVANNI, 2003, p. 214). 
Muitos dos valores que tivemos no passado precisam ser revigorados; ser moderno não é abandonar o que já passou. $O$ que temos de proteger e levar adiante chamamos de "tradicional", e o que temos de destacar e abandonar chamamos de "arcaico".

Assim, há valores tradicionais e valores arcaicos. Considero tradicionais aqueles que são universais (amorosidade, lealdade, integridade, disciplina, esforço honesto), esses precisam servir de referência para as vidas.

\section{A ESCOLA REFLEXIVA E SUA IMPORTÂNCIA NA FORMAÇÃO DA CIDADANIA DOS ALUNOS}

O professor não pode agir isoladamente na sua escola. É neste local, o seu local de trabalho, que ele, com os outros, seus colegas, constrói a profissionalidade docente. Mas se a vida dos professores tem o seu contexto próprio, a escola, esta tem de ser organizada de modo a criar condições de reflexividade individuais e coletivas. Vou ainda longe. A escola tem de se pensar a si própria, na sua missão e no modo como se organiza para a cumprir. Tem, também ela, de ser reflexiva.

Mas o que é a escola? Uma comunidade educativa, um grupo social constituído por alunos, professores e funcionários e fortes ligações à comunidade envolvente através dos pais e dos representantes do poder municipal. A ideia do professor reflexivo, que reflete em situação e constrói conhecimento a partir do pensamento sobre a sua prática é perfeitamente transponível para a comunidade educativa que é a escola.

[...] o lado objetivo da prática pedagógica é constituído pelo conjunto de meios, o modo pelo qual as teorias pedagógicas são colocadas em ação pelo professor. O que as distingue da teoria é o caráter real, objetivo, da matéria-prima sobre a qual ela atua dos meios ou instrumentos com que se exerce a ação, e de seu resultado ou produto. Sua finalidade é a transformação real, objetiva de modo natural ou social, satisfazer determinada atividade humana (VEIGA, 2008, p. 17).

Se a capacidade reflexiva é inata no ser humano, ela necessita de contextos que favoreçam o seu desenvolvimento, contextos de liberdade e responsabilidade. É repetidamente afirmado, nos estudos em que o fator da reflexão é tido em consideração, a dificuldade que os participantes revelam em pôr em ação os mecanismos reflexivos, sejam eles crianças, adolescentes ou adultos. É preciso vencer inércias, é preciso vontade e persistência. É preciso fazer um esforço grande para passar o nível em que se buscam interpretações articuladas e justificadas e sistematizações cognitivas.

$\mathrm{Na}$ educação, um efeito deste movimento são os processos de descentralização da gestão escolar, hoje percebidos como uma das mais importantes tendências das formas 
educacionais em nível mundial e um tema importante na formação continuada dos docentes e nos debates educacionais com toda a sociedade.

As mudanças vividas na atualidade em nível mundial, em termos econômicos, sociais e culturais, com a transnacionalização da economia e o intercâmbio quase imediato de conhecimento e padrões sociais e culturais, através das novas tecnologias da comunicação, entre outros fatores, têm provocado uma nova atuação dos Estados nacionais na organização das políticas pública por meio de um movimento de repasse de poderes e responsabilidades dos governos centrais para as comunidades locais.

Os problemas de aprendizagem se manifestam de diferentes formas dentro da escola, e sintomas divergentes se apresentam para revelar que algo não vai bem. Cada criança é única na sua forma de ser, de aprender, bem como de não aprender. Perguntamo-nos, enquanto docentes, por que alguns conseguem aprender e outros não, se a forma de ensinar é a mesma.

Entretanto, certamente não são os mesmos os vínculos entre professor e todos os alunos, porque cada criança tem um temperamento, comportamento, família, culturas diferentes. Alunos que conversão muito, se desconcentram e não participam são chamados a atenção, que, quase sempre, são carregadas de broncas e ameaças, destruindo a autoestima da criança, e um vínculo que é fundamental para a aprendizagem. Mas não é somente o aluno que sai prejudicado nesta relação conturbada; o professor também apresenta sintomas que interferem no seu equilíbrio.

De acordo com pesquisas do instituto Acadêmico de Inteligência, no Brasil, $92 \%$ dos professores estão com três ou mais sintomas de estresse e $41 \%$ com dez ou mais. É um número altíssimo, indicando que quase a metade dos professores não deveria estar em sala de aula, mas internada em uma clínica ante estresse. (CURY, p.62. 2003,)

Araújo (2003) adverte:

Identificar estes períodos é de grande relevância para o trabalho pedagógico, pois é baseado neles que o professor saberá quais atividades mais adequadas para cada idade. É este um dos grandes problemas enfrentados pelos alunos e que aparentemente ainda não foram solucionados. Professores aplicam problemas matemáticos correspondentes ao nível de inteligência operatória formal (a partir dos 12 anos) para que estas crianças, que ainda atuam no operatório concreto, tendem solucionar. Levantar hipóteses, fazer suposições ainda não correspondem a esta faixa etária, isto só irá acontecer mais tarde. 
Neste contexto foi apresentado no espaço escolar as seguintes indagações que buscam evidenciar a importância da escola reflexiva para a formação da cidadania no ambiente escolar.

1- Quais destes fatores influenciam para que ocorram ações reflexivas no contexto escolar.

Tabela 01 - Fatores influenciam para que ocorram ações reflexivas no contexto escolar.

\begin{tabular}{|l|c|c|c|c|c|c|}
\hline \multirow{2}{*}{\multicolumn{1}{c|}{ Variável }} & \multicolumn{7}{c|}{ Sujeitos } \\
\cline { 2 - 8 } & \multicolumn{2}{|c|}{ Coordenação } & \multicolumn{2}{c|}{ Docente } & \multicolumn{2}{c|}{ Discente } \\
\cline { 2 - 7 } & Fn & F\% & Fn & F\% & Fn & F\% \\
\hline a participação dos pais & - & - & 19 & $34 \%$ & 102 & $67 \%$ \\
\hline O trabalho coletivo & - & - & 18 & $32 \%$ & 14 & $10 \%$ \\
\hline A autonomia do professor & - & - & - & - & 04 & $02 \%$ \\
\hline A gestão participativa & - & - & - & - & 02 & $01 \%$ \\
\hline Todas as opções & 08 & $100 \%$ & 19 & $34 \%$ & 30 & $20 \%$ \\
\hline Total & 08 & $100 \%$ & 56 & $100 \%$ & 152 & $100 \%$ \\
\hline
\end{tabular}

Fonte: Elaboração própria da autora. Mardiled Tânia Vilhena Vieira Gomes

Interpretação: Conforme se observa na tabela $\mathrm{n}$ ㅇ 01, que traz informações referente a quais destes fatores influenciam para que ocorra ações reflexivas no contexto escolar, observa-se que na categoria coordenação $100 \%$ dos entrevistados responderam todas as opções.

Já na categoria docente 34\% responderam a participação dos pais, 34\% responderam todas as opções e $32 \%$ responderam o trabalho coletivo.

E na categoria discente $67 \%$ responderam a participação dos pais, $20 \%$ responderam todas as opções, $10 \%$ responderam o trabalho coletivo, $02 \%$ responderam a autonomia do professor e $01 \%$ responderam a gestão participativa.

\section{2- Efeitos da escola reflexiva para formação discente}

Tabela 02 - Efeitos da escola reflexiva para formação discente.

\begin{tabular}{|l|c|c|c|c|c|c|}
\hline \multirow{2}{*}{ Variável } & \multicolumn{6}{c|}{ Sujeitos } \\
\cline { 2 - 7 } & \multicolumn{1}{|c|}{ Coordenação } & \multicolumn{2}{c|}{ Docente } & \multicolumn{2}{c|}{ Discente } \\
\cline { 2 - 7 } & Fn & F\% & Fn & F\% & Fn & F\% \\
\hline $\begin{array}{l}\text { A escola deixou de ser o único espaço } \\
\text { de aprendizagem }\end{array}$ & 08 & $100 \%$ & 38 & $68 \%$ & 141 & $93 \%$ \\
\hline $\begin{array}{l}\text { A palavra do docente deixou de ser o } \\
\text { único suporte de ensino }\end{array}$ & - & - & 18 & $32 \%$ & 11 & $07 \%$ \\
\hline $\begin{array}{l}\text { O docente não se sente preparado para } \\
\text { trabalhar com a diversidade global }\end{array}$ & - & - & - & - & - & - \\
\hline Total & 08 & $100 \%$ & 56 & $100 \%$ & 152 & $100 \%$ \\
\hline
\end{tabular}

Fonte: Elaboração própria da autora. Mardiled Tânia Vilhena Vieira Gomes 
Interpretação: Conforme se observa na tabela $\mathrm{n}^{\circ} 02$, que traz informações referente aos efeitos da escola reflexiva para formação discente, observa-se que na categoria coordenação 100\% responderam a escola deixou de ser o único espaço de aprendizagem.

Já na categoria docente $68 \%$ responderam a escola deixou de ser o único espaço de aprendizagem e $32 \%$ responderam a palavra do docente deixou de ser o único suporte de ensino.

E na categoria discente $93 \%$ responderam a escola deixou de ser o único espaço de aprendizagem e 07\% responderam a palavra do docente deixou de ser o único suporte de ensino.

\section{3- A escola reflexiva promover na formação discente?}

Tabela 03 - Escola reflexiva promover na formação discente

\begin{tabular}{|l|c|c|c|c|c|c|}
\hline \multirow{2}{*}{\multicolumn{1}{c|}{ Variável }} & \multicolumn{9}{c|}{ Sujeitos } \\
\cline { 2 - 8 } & \multicolumn{2}{|c|}{ Coordenação } & \multicolumn{2}{c|}{ Docente } & \multicolumn{2}{c|}{ Discente } \\
\cline { 2 - 8 } & Fn & F\% & Fn & F\% & Fn & F\% \\
\hline Formação do pensamento crítico & 08 & $100 \%$ & 38 & $68 \%$ & 117 & $77 \%$ \\
\hline Autonomia & - & - & - & - & - & - \\
\hline A participação & - & - & 18 & $32 \%$ & 14 & $10 \%$ \\
\hline A formação global & - & - & - & - & 21 & $13 \%$ \\
\hline Total & 08 & $100 \%$ & 56 & $100 \%$ & 152 & $100 \%$ \\
\hline
\end{tabular}

Fonte: Elaboração própria da autora. Mardiled Tânia Vilhena Vieira Gomes

Interpretação: Conforme se observa na tabela no 03, que traz informações referente ao questionamento se a escola reflexiva promover na formação discente observa-se que categoria coordenação 100\% responderam formação do pensamento crítico.

Já na categoria docente $68 \%$ responderam formação do pensamento crítico e $32 \%$ responderam a participação.

E na categoria discente $77 \%$ responderam formação do pensamento crítico, $13 \%$ responderam a formação global e 10\% responderam a participação.

\section{4- Quais são os benefícios da escola reflexiva na formação discente?}

Tabela 04- Os benefícios da escola reflexiva na formação discente

\begin{tabular}{|l|c|c|c|c|c|c|}
\hline \multirow{2}{*}{\multicolumn{1}{c|}{ Variável }} & \multicolumn{9}{c|}{ Sujeitos } \\
\cline { 2 - 8 } & \multicolumn{2}{|c|}{ Coordenação } & \multicolumn{2}{c|}{ Docente } & \multicolumn{2}{c|}{ Discente } \\
\cline { 2 - 8 } & Fn & F\% & Fn & F\% & Fn & F\% \\
\hline Pouca evasão escolar & - & - & 18 & $32 \%$ & 04 & $02 \%$ \\
\hline O controle da baixa repetência & - & - & - & - & 25 & $17 \%$ \\
\hline Aprendizagem dos conteúdos & - & - & - & - & 23 & $15 \%$ \\
\hline Formação do pensamento crítico & 08 & $100 \%$ & 38 & $68 \%$ & 100 & $66 \%$ \\
\hline Total & 08 & $100 \%$ & 56 & $100 \%$ & 152 & $100 \%$ \\
\hline
\end{tabular}

Fonte: Elaboração própria da autora. Mardiled Tânia Vilhena Vieira Gomes 
Interpretação: Conforme se observa na tabela nำ04, que traz informações referente a quais são os benefícios da escola reflexiva na formação discente, observa-se que na categoria coordenação 100\% responderam formação do pensamento crítico.

Já na categoria docente $68 \%$ responderam formação do pensamento crítico e $32 \%$ responderam pouca evasão escolar. E na categoria discente $66 \%$ responderam formação do pensamento crítico, 17\% responderam o controle de baixa repetência, 15\% responderam aprendizagem dos conteúdos e02\% responderam pouca evasão escolar.

\section{5- Que papel tem a escola reflexiva?}

Tabela 05 - O papel da escola reflexiva

\begin{tabular}{|l|c|c|c|c|c|c|}
\hline \multirow{2}{*}{\multicolumn{1}{c|}{ Variável }} & \multicolumn{9}{c|}{ Sujeitos } \\
\cline { 2 - 8 } & \multicolumn{1}{|c}{ Coordenação } & \multicolumn{2}{c|}{ Docente } & \multicolumn{2}{c|}{ Discente } \\
\cline { 2 - 8 } & Fn & F\% & Fn & F\% & Fn & F\% \\
\hline Papel meramente informativo & - & - & - & - & - & - \\
\hline Papel transformador e formador & 08 & $100 \%$ & 56 & $100 \%$ & 100 & $66 \%$ \\
\hline Papel instrutivo & - & - & - & - & 52 & $34 \%$ \\
\hline Papel burocrático & - & - & - & - & - & - \\
\hline Total & 08 & $100 \%$ & 56 & $100 \%$ & 152 & $100 \%$ \\
\hline
\end{tabular}

Fonte: Elaboração própria da autora. Mardiled Tânia Vilhena Vieira Gomes

Interpretação: Conforme se observa na tabela no 05 , que traz informações referente a que papel tem a escola reflexiva, observa-se que na categoria coordenação $100 \%$ responderam papel transformador e formador. Já na categoria docente $100 \%$ responderam papel transformador e formador. E na categoria discente $66 \%$ responderam papel transformador e formador e $45 \%$ responderam papel instrutivo.

\section{6- Quais as maiores dificuldades encontrada na prática pedagógica docente para trabalhar com a ação reflexiva?}

Tabela 06 - Dificuldades encontrada na prática pedagógica docente para trabalhar com a ação reflexiva

\begin{tabular}{|l|c|c|c|c|c|c|}
\hline \multirow{2}{*}{\multicolumn{1}{|c|}{ Variável }} & \multicolumn{7}{c|}{ Sujeitos } \\
\cline { 2 - 7 } & \multicolumn{2}{|c|}{ Coordenação } & \multicolumn{2}{c|}{ Docente } & \multicolumn{2}{c|}{ Discente } \\
\cline { 2 - 7 } & Fn & F\% & Fn & F\% & Fn & F\% \\
\hline Falta de recursos & - & - & 19 & $34 \%$ & 11 & $07 \%$ \\
\hline Falta de formação & - & - & - & - & - & - \\
\hline Falta de autonomia docente & - & - & - & - & 16 & $10 \%$ \\
\hline Falta de compreensão da família & - & - & 19 & $34 \%$ & 20 & $13 \%$ \\
\hline $\begin{array}{l}\text { Falta de um trabalho coletivo e } \\
\text { participativo }\end{array}$ & 08 & $100 \%$ & 18 & $32 \%$ & 105 & $70 \%$ \\
\hline Total & 08 & $100 \%$ & 56 & $100 \%$ & 152 & $100 \%$ \\
\hline
\end{tabular}

Fonte: Elaboração própria da autora. Mardiled Tânia Vilhena Vieira Gomes 
Interpretação: Conforme se observa na tabela nํㅜ 06, que traz informações referente a quais as maiores dificuldades encontrada na prática pedagógica docente para trabalhar com a ação reflexiva, observa-se que na categoria coordenação $100 \%$ responderam falta de um trabalho coletivo e participativo.

Já na categoria docente $34 \%$ responderam falta de recursos, 34\% responderam falta de compreensão da família e $32 \%$ responderam falta de um trabalho coletivo e participativo.

E na categoria discente $70 \%$ responderam falta de um trabalho coletivo e participativo, 13\% responderam falta de compreensão da família, 10\% responderam falta de autonomia docente e $07 \%$ responderam falta de recursos.

\section{7- Nas escolhas de temáticas e/ou conceitos de ensino há a autonomia dos professores para direcionarem suas opiniões?}

Tabela 07 - Temáticas e/ou conceitos de ensino há a autonomia dos professores para direcionarem suas opiniões

\begin{tabular}{|l|c|c|c|c|c|c|c|}
\hline \multirow{2}{*}{\multicolumn{2}{c|}{ Variável }} & \multicolumn{9}{c|}{ Sujeitos } \\
\cline { 2 - 8 } & \multicolumn{2}{|c|}{ Coordenação } & \multicolumn{2}{c|}{ Docente } & \multicolumn{2}{c|}{ Discente } \\
\cline { 2 - 8 } & Fn & F\% & Fn & F\% & Fn & F\% \\
\hline Sim & - & - & 38 & $68 \%$ & - & - \\
\hline Não & - & - & - & - & - & - \\
\hline As vezes & 08 & $100 \%$ & 18 & $32 \%$ & - & - \\
\hline Raramente & - & - & - & - & - & - \\
\hline Total & 08 & $100 \%$ & 56 & $100 \%$ & - & - \\
\hline
\end{tabular}

Fonte: Elaboração própria da autora. Mardiled Tânia Vilhena Vieira Gomes

Interpretação: Conforme se observa na tabela no 07, que traz informações referente a se nas escolhas de temáticas e/ou conceitos de ensino há a autonomia dos professores para direcionarem suas opiniões, observa-se que na categoria coordenação $100 \%$ responderam as vezes.

Já na categoria docente $68 \%$ responderam sim e 32\% responderam as vezes.

A categoria discente se absteve dessa interrogante.

\section{CONSIDERAÇÕES FINAIS}

Afim de averiguar o papel da escola reflexiva e como está contribui para a formação da cidadania do aluno no decorrer do processo educativo, para compreender essa relação foi elaborado um grupo de interrogante buscando respostas diante das categorias docência, coordenação e discência.

Portanto, evidencia-se que a participação dos pais, o trabalho coletivo, a autonomia do professor, a gestão participativa, são fatores fundamentais a serem desenvolvidos no 
ambiente escolar para que ocorra a ação reflexiva. A prática reflexiva no ambiente escolar depende da participação e envolvimento de todos os seguimentos escolares e não escolares atuando de forma coletiva para que haja a melhoria da educação.

A prática educativa reflexiva é uma ação fundamental para que haja a realização de ações e projetos que primem para a melhoria da educação.

Evidenciou-se que para grande maioria dos sujeitos participantes a escola deixou de ser o único espaço de aprendizagem. Hoje o aluno tem grande acesso de informações através da conectividade, o aluno está conectado com o mundo e através dos recursos midiáticos o aluno vivencia as mudanças que ocorrem de forma global. $E$ esse acesso permite a formação da criticidade do aluno;

Portanto a escola reflexiva busca formar o aluno como sujeito pensante, que haja com criticidade, reconhecendo seus direitos e deveres, fazendo intervenções no mundo.

Portanto é notório a importância da escola reflexiva para formação da cidadania do aluno, e está só será evidenciada na formação do aluno se ele perpassar por uma ação formativa que o leve a se desenvolver de forma crítica, sendo capa dez utilizar a dialogicidade, de agir com autonomia, de se fazer ouvir coo sujeito de direitos e deveres, portanto a escola reflexiva visa formar o aluno crítico.

Portanto, conclui-se que a escola reflexiva tem um papel transformador e formador. A escola reflexiva precisa proporcionar a melhoria de seus sujeitos, de sua comunidade afirmando-se como instituição educacional mais a serviço do social a formar cidadão compromissados com a transformações de seu espaço enquanto sujeitos sócio culturais.

Portanto evidenciou-se que para o professor ensinar o aluno estimulando o desenvolvimento do seu pensamento crítico, é preciso utilizar metodologias que envolvam a partia lúdica, perpassando ainda pelo interesse e compromisso docente além do investimento em livros que permitam ao aluno conhecimentos que sejam significativos e estejam contextualizados.

O disparador principal do processo ensino-aprendizagem é o problema ou situação problema. O problema coloca o aluno no centro do processo, como protagonista. (AQUILANTE et al. 2011, p. 148).

Evidenciou-se que as maiores dificuldades apontadas pelos participantes, encontrada na prática pedagógica docente para trabalhar com a ação reflexiva está ligada a ausência do trabalho coletivo e participativo, seguidos pela ausência de recursos e a falta de participação da família. Para LEONTIEV (1978) é no trabalho em grupo que os indivíduos desenvolvem a consciência. Daí a importância da coletividade na sala de aula.

Conclui-se que sobre as escolhas de temáticas e/ou conceitos de ensino a autonomia dos professores j se faz presente para direcionarem suas opiniões. Portanto, os educadores já participam diretamente contribuindo com seu pesar para melhoramento das 
propostas de ensino. Segundo FREIRE (2014), o professor necessita insistir no seu processo de aprendizagem, refletir que ensinar não e transferir conhecimento e nem somente aprendido por parte do professor e do aluno em suas razões de ser.

\section{REFERÊNCIAS}

ALARCÃO, I.; TAVARES, J. Supervisão da prática pedagógica. Uma perspectiva de desenvolvimento e aprendizagem. Coimbra: Almedina, 1987. (2 $2^{\mathrm{a}}$ edição, amplamente desenvolvida, 2003).

ALARCÃO, Isabel. Professores reflexivos em uma escola reflexiva / Isabel Alarcão. - 8. Ed. - São Paulo: Cortez, 2011. - (Coleção questões da nossa época; v. 8)

ANTUNES, Celso. Relações interpessoais e autoestima: a sala de aula como um espaço do crescimento integral, fascículo 16 / Celso Antunes, - Petrópolis, RJ: Vozes, 2003.

AQUILANTE, A. G. et al. Situações-problema simuladas: uma análise do processo de construção. Revista Brasileira de Educação Médica, v. 35, n. 2, p. 147-156, 2011.

CURY, Augusto Jorge. Pais brilhantes, professores fascinantes. Rio de Janeiro: Sextante, 2003.

DEUS, Adélia Meireles de; MENDES, Bárbara Maria Macêdo. Formação de professores: valorizar e ater- se ao essencial do currículo e da prática pedagógica. In: MENDES SOBRINHO, José Augusto de Carvalho; LIMA, Maria da Glória Soares Barbosa. Formação, prática pedagógica e pesquisa em educação: retratos e relatos. Teresina: EDUFPI, 2011. p. 133- 151.

FREIRE. P. Pedagogia Da Autonomia. Rio De Janeiro /São Paulo: Editora Paz \&Terra, 2014.

GIOVANNI, Luciana Maria. O ambiente escolar e ações de formação continuada. In: TIBALLI, E. F. A; CHAVES, S. M. (Org.). Concepções e práticas em formação de professores: diferentes olhares. Rio de Janeiro: DP\&A, 2003. p. 207-224.

LEITE, Lígia Silva (coord.). Tecnologia educacional: descubra suas possibilidades na sala de aula. 5. ed. Petrópolis: Vozes, 2010.

LEONTIEV, A. O desenvolvimento do psiquismo. Lisboa: Livros Horizontes, 1978.

VEIGA, Ilma Passos Alencastro. A prática pedagógica do professor de Didática. 11.ed. Campinas, SP: Papirus, 2008 